\title{
Numerical Simulation of a Bradley Mini- Hydrocyclone
}

\author{
Rodrigo P. Anjos, Rafael S. Oliveira, Ricardo A. Medronho
}

\begin{abstract}
Hydrocyclones are compact devices employed mainly for solid-liquid separation. $\mathrm{CaCO}_{3}$ separation from a $1 \% \mathrm{v} / \mathrm{v}$ aqueous suspension using a $15 \mathrm{~mm}$ diameter Bradley mini-hydrocyclone was studied both numerically and experimentally. The aim of this study was to compare experimental data with those obtained numerically, using three different approaches: stationary, pseudo transient and transient. Pressure and tangential velocity profiles, pressure drops, flow ratios, reduced grade efficiency curves, reduced cut sizes and reduced total efficiencies were compared. The simulated results agree for transient and pseudo transient regimes, and there is a reasonable agreement when comparing numerical and experimental data.
\end{abstract}

Keywords - CFD, Hydrocyclones, Pseudo transient method

\section{Introduction}

Computational fluid dynamics (CFD) is a tool that allows numerical solutions, by computational methods, of the conservation equations of mass and momentum, eventually coupled to other conservation equations such as energy and concentration of a given chemical species.

With the improvement of computational methods and computer power, CFD has been increasing its importance in design and performance evaluation of various devices used in the chemical industry. Thus, the study of hydrocyclones using CFD has also grown. However, there are still doubts concerning the best procedure to conduct the simulations for that equipment, stationary, pseudo-transient or transient.

Schuetz et al. [1] claim that simulations conducted under steady state conditions lead to pressure and velocity profiles which change periodically. Thus, they simulated in transient regime and obtained good agreement between experimental and simulated data. Other authors also validated transient simulations conducted in hydrocyclones [2 to 4]. However, only one of the studies [2] presents high inlet velocities, greater than $5 \mathrm{~m} \mathrm{~s}^{-1}$, similar to the velocities employed in the present work.

\section{CFD Modeling}

In this study, continuity and momentum conservation equations were solved with Reynolds-averaged NavierStokes equations (RANS) for incompressible, single phase and Newtonian flows (Equations 1 and 2).

Rodrigo P. Anjos, Rafael S. Oliveira, Ricardo A. Medronho Chem. Eng. Dept., School of Chemistry, Universidade Federal do Rio de Janeiro

Brazil

$$
\begin{gathered}
\frac{\partial U_{i}}{\partial x_{i}}=0 \\
\frac{\partial U_{i}}{\partial t}+U_{j} \frac{\partial U_{i}}{\partial x_{j}}=\frac{1}{\rho} \frac{\partial P}{\partial x_{i}}+\frac{\partial}{\partial x_{j}}\left(v \frac{\partial U_{i}}{\partial x_{j}}-\overline{u_{i} u_{j}}\right)
\end{gathered}
$$

where $U$ is the time-averaged velocity, $u$ is the fluctuating velocity, $\rho$ is the fluid density, $P$ is the mean pressure, and $v$ is the kinematic viscosity.

Using RANS equations requires a turbulence model for the closure of the equation system due Reynolds tensors. For that, different models such as the $\kappa-\varepsilon$ and Reynolds stress models (RSM) may be used. Some authors [4 to 6] showed better agreement with experimental data for hydrocyclones CFD simulations when RSM were adopted as turbulence model.

Slack et al. [7] evaluated the best turbulence model to simulate cyclones, Large Eddy Simulation (LES), which does not use RANS approach, or RSM. They still pointed out that good results are just reached when the turbulence models are able to consider anisotropy and nonequilibrium effects, as cyclones have fluids in rotation and threedimensional boundary layer with curved streamlines. Those authors concluded that both models exhibited good agreement with experimental data. Nevertheless, LES model, as stated by [6], requires high computational power and are impractical for many applications. Thus, the Gibson and Launder RSM [8] was used in the study, and the EulerEuler approach was chosen, in which both phases are treated as continuous. The equations solved by this approach are presented in [9].

Regarding pseudo transient aproach, it comes from the relaxation concept. It is used for cases in which it is desired to accelerate or slow changes in a given variable. Underelaxation is widely used in cases of significant nonlinearity to avoid divergence as explained by [9]. Versteeg and Malalasekera [10] recommend pseudo transient setting for cases with high rotational flow. In the transient simulations, time step was $10^{-4} \mathrm{~s}$.

Other adopted configurations were: second order upwind for momentum, turbulent kinetic energy, turbulent dissipation rate and Reynolds stresses spatial discretization, QUICK for volume fraction spatial discretization and least square cell based for gradient spatial discretization. Pressure-velocity coupling were solved with a coupled solver. The boundary conditions were constant velocity at inlet and constant pressure at both outlets.

The meshes were built using hexahedral elements in order to reduce numerical errors [9]. 


\section{Materials and Methods}

This work compared simulation data in different regimes for a small Bradley hydrocyclone, which was employed for water-calcium carbonate separation. Furthermore, the simulation results are compared to experimental data [11, 12].

The simulations were performed using Fluent, version 13.0, from Ansys. A microcomputer with intel quad core processor of $2.8 \mathrm{GHz}$, physical memory of $500 \mathrm{~GB}$ and RAM memory of $4 \mathrm{~GB}$ was used to make geometry and mesh as well as to analyse data. Moreover, a node of a cluster ALTIX XEI 300 Quad-core (168 cores, 168 GB Mem), Infiniband, IS350 8TB was employed to perform simulations. The node contains an Intel Xeon quad-core processor of $2.33 \mathrm{GHz}$, physical memory of $250 \mathrm{~GB}$ and RAM memory of 4 GB.

\section{A. Geometry}

The geometry of the Bradley mini-hydrocyclone was made using Design Modeler, version 13.0, from Ansys. The dimensions of the studied hydrocyclone are presented in Table I and illustrated in Fig. 1.

TABLE I. DIMENSIONS OF THE STUDIED HYDROCYCLONE ACCORDING TO FIG. 1.

\begin{tabular}{|l|c|}
\hline \multicolumn{1}{|c|}{ Geometric variable } & Values \\
\hline Overflow diameter (Do) & 0.30 \\
\hline Underflow diameter (Du) & 0.20 \\
\hline Cylinder diameter (Dc) & 1.50 \\
\hline Inlet diameter (Di) & 0.20 \\
\hline Cylindrical length section (L1) & 0.75 \\
\hline Wall thickness (L3) & 0.05 \\
\hline Underflow length (L6) & 1.50 \\
\hline Overflow length (L2+L5) & 1.50 \\
\hline Inlet length (L7) & 1.50 \\
\hline Conical section length (L4) & 8.26 \\
\hline Vortex finder length (L2) & 0.5 \\
\hline \hline Conical section angle ( $\theta)$ & $9^{\circ}$ \\
\hline
\end{tabular}

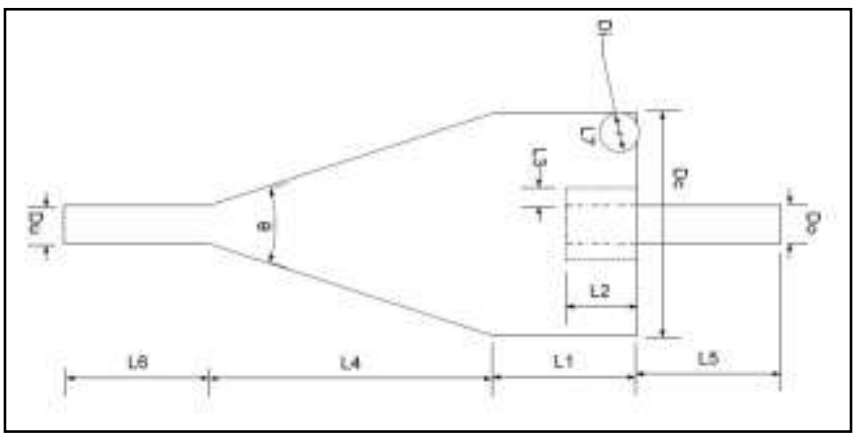

Figure 1. Geometric parameters of the hydrocyclone.

\section{B. Meshes}

All meshes were constructed in ICEM CFD, version 13.0, from Ansys. The meshes were refined near the central region of the hydrocyclone due to the complex reverse rotational flow and, therefore, high velocity and pressure gradients. They were also refined near wall due to high velocity gradients present there. As results obtained from numerical solution may be sensitive to the number of mesh elements and on the other hand increasing these implies increasing computational effort, a grid independence test was conducted. As a result of this test, it was determined that the optimal mesh should present 342,800 elements and 332,845 nodes (Fig. 2).

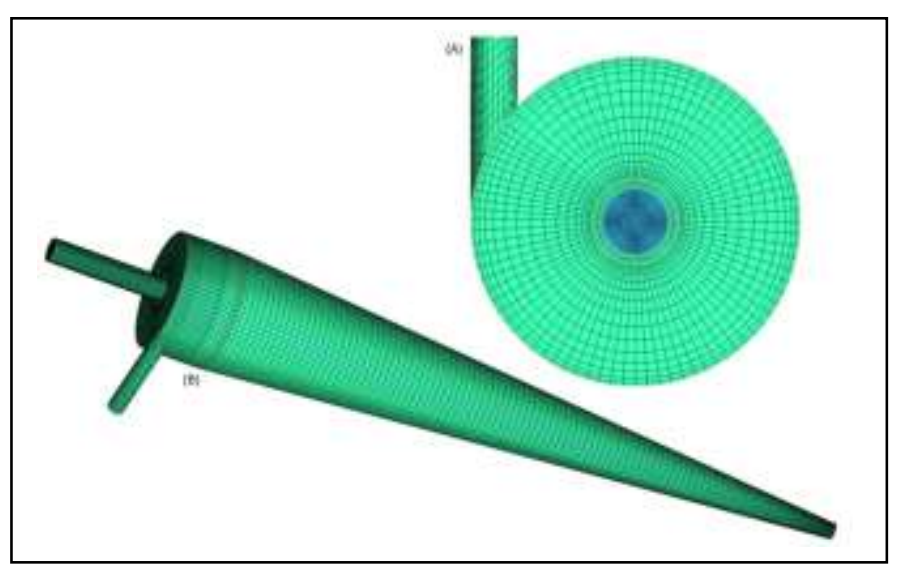

Figure 2. Mesh representation: (A) Top view; (B) Perspective view.

\section{Simulation Description: Physical Properties, Boundary Conditions and Convergence Criteria}

Simulations were conducted for four different cases, which differ in inlet velocity and dynamic viscosity (Table II).

TABLE II. INLET VELOCITIES AND WATER DENSITY AND VISCOSITY FOR EACH STUDIED CASE.

\begin{tabular}{|c|c|c|}
\hline Case & $\begin{array}{c}\text { Inlet Velocity } \\
\left(\mathbf{c m ~ s}^{\mathbf{- 1}}\right)\end{array}$ & $\begin{array}{c}\text { Viscosity } \\
(\mathbf{c P})\end{array}$ \\
\hline 1 & 840 & 7.6 \\
\hline 2 & 1130 & 7.7 \\
\hline 3 & 1300 & 7.7 \\
\hline 4 & 1480 & 7.9 \\
\hline
\end{tabular}

In all cases, single-phase simulations were carried out in pseudo-transient and transient regimes (steady state was only simulated for case 3) and the profiles of tangential velocity were compared. Furthermore, pressure drops and flow ratios (flow ratio is the ratio between water flow rate in the underflow and feed) were compared with experimental values of Silva and Medronho [11] obtained with aqueous suspensions of calcium carbonate, $1 \%$ by volume.

Two phase simulations were also conducted. The reduced grade efficiency versus particle size curves were compared for pseudo transient and transient regimes. Moreover, the reduced cut sizes and reduced total efficiencies were also compared with experimental values [11].

All simulations were isothermal and calcium carbonate density was $2.45 \mathrm{~g} \mathrm{~cm}^{-3}$. 


\section{Iv. Results and Discussion}

\section{A. Single-Phase Simulations}

Numeric simulations using water only were carried out using three different regimes, stationary, pseudo transient and transient. Comparisons were performed after fifteen thousand iterations for stationary and pseudo transient simulations and, for the transient simulations, after a real time of 0.3 s. Fig. 3 illustrates this comparison of all simulated regimes, showing the tangential velocity in the central plane for the three schemes simulated for case 3 .

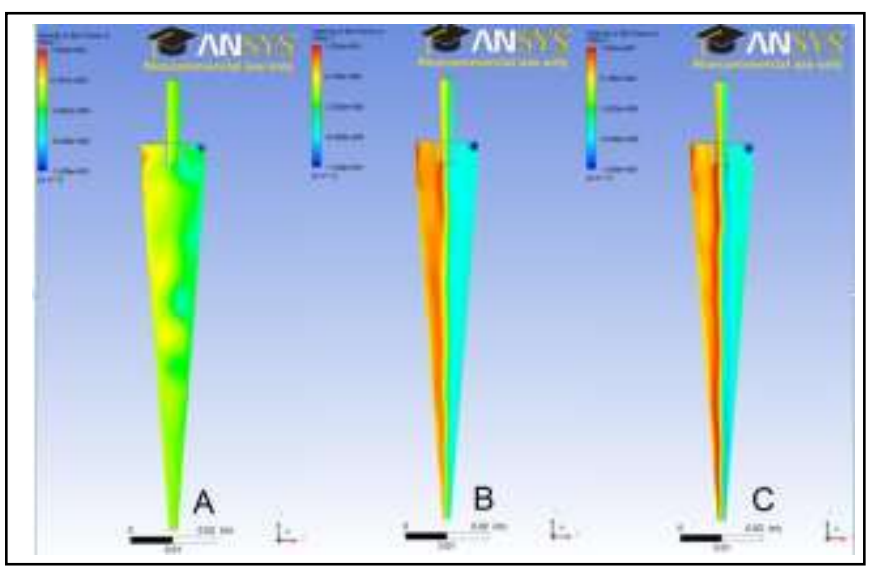

Figure 3. Hydrocyclone central plane colored with tangential velocity for the three studied regimes (case 3): A: stationary, B: pseudotransient and C: transient.

The tangential velocity profiles for pseudo transient and transient regimes are similar and agrees with the expected profile. In contrast, the stationary regime presents a wrong profile. It can be concluded that stationary regime simulations do not represent properly the physics of flow inside hydrocyclones. That is why all other results in this study were obtained using pseudo transient and transient regimes only.

Table III presents simulated and experimental pressure drop values, whereas Table IV does the same for flow ratio.

TABLE III. EXPERIMENTAL AND SIMULATED (PSEUDO TRANSIENT AND TRANSIENT REGIMES) VALUES FOR PRESSURE DROP $(\Delta \mathrm{P})$.

\begin{tabular}{|c|c|c|c|c|c|}
\hline Case & $\begin{array}{c}\Delta \mathbf{P}_{\text {experim. }} \\
(\mathbf{k P a})\end{array}$ & $\begin{array}{c}\Delta \mathbf{P}_{\text {pse trans }} \\
(\mathbf{k P a})\end{array}$ & $\begin{array}{c}\Delta_{\text {pse trans }} \\
(\mathbf{\%})\end{array}$ & $\begin{array}{c}\Delta \mathbf{P}_{\text {transient }} \\
(\mathbf{k P a})\end{array}$ & $\begin{array}{c}\Delta_{\text {transient }} \\
(\mathbf{\%})\end{array}$ \\
\hline 1 & 69.0 & 83.1 & 20.4 & 83.1 & 20.4 \\
\hline 2 & 138.0 & 139.5 & 1.1 & 166.2 & 20.4 \\
\hline 3 & 207.0 & 191.3 & -7.6 & 191.1 & -7.7 \\
\hline 4 & 276.0 & 311.9 & 13.0 & 311.7 & 12.9 \\
\hline
\end{tabular}

TABLE IV. EXPERIMENTAL AND SIMULATED (PSEUDO TRANSIENT AND TRANSIENT REGIMES) VALUES FOR FLOW RATIO $\left(\mathrm{R}_{\mathrm{F}}=\right.$ RATIO BETWEEN WATER FLOW RATE IN THE UNDERFLOW AND FEED).

\begin{tabular}{|c|c|c|c|c|c|}
\hline Case & $\begin{array}{c}\mathbf{R}_{\text {f experim. }} \\
(\mathbf{\%})\end{array}$ & $\begin{array}{c}\mathbf{R}_{\text {f pse trans }} \\
(\mathbf{\%})\end{array}$ & $\begin{array}{c}\Delta_{\text {pse trans }} \\
(\mathbf{\%})\end{array}$ & $\begin{array}{c}\mathbf{R}_{\text {f transient }} \\
(\mathbf{\%})\end{array}$ & $\begin{array}{c}\Delta_{\text {transient }} \\
(\mathbf{\%})\end{array}$ \\
\hline 1 & 30.3 & 29.0 & -4.0 & 29.1 & -4.0 \\
\hline 2 & 27.8 & 33.5 & 20.3 & 25.9 & -7.1 \\
\hline 3 & 28.0 & 28.2 & 0.9 & 28.2 & -0.9 \\
\hline 4 & 27.4 & 23.2 & -15.4 & 23.5 & -14.0 \\
\hline
\end{tabular}

Tables III and IV show a relatively good agreement between experimental and simulated values (both for pseuso transient and transient) for the pressure drop and flow ratio.

\section{B. Two-Phase Simulations}

In the two-phase simulations, comparisons carried out performed also after fifteen thousand iterations for pseudo transient and, for transient simulations, after a the real time $0.3 \mathrm{~s}$.

Fig. 4 shows that the reduced grade efficiency curves are practically identical for pseudo transient and transient regimes. Again, simulations in both regimes are equivalent.

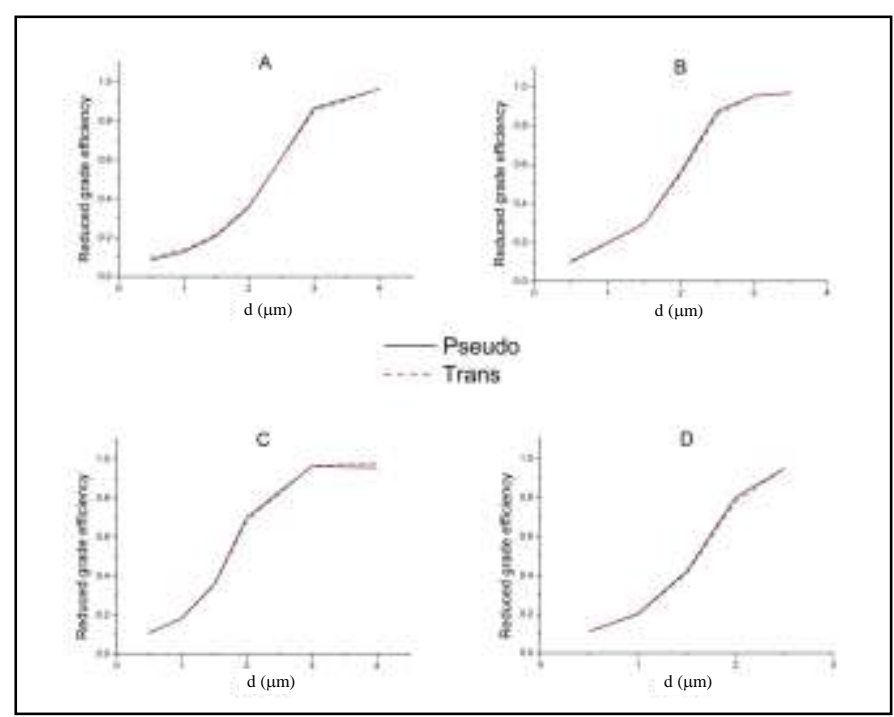

Figure 4. Reduced grade efficiency curves. A - case1; B - case 2; C - case 3; D- case 4 .

Table V and VI present a comparison between experimental and simulated results for the reduced cut size and the reduced total efficiency, respectively.

TABLE V. EXPERIMENTAL AND SIMULATED (PSEUDOTRANSIENT AND TRANSIENT REGIMES) REDUCED CUT SIZE (D' ${ }_{50}$ ).

\begin{tabular}{|c|c|c|c|c|c|}
\hline Case & $\begin{array}{c}d^{\prime} \text { 50experim. } \\
(\mu \mathrm{m})\end{array}$ & $\begin{array}{c}\mathbf{d}_{\text {50pse trans }} \\
(\mu \mathrm{m})\end{array}$ & $\begin{array}{c}\Delta_{\text {pse trans }} \\
(\%)\end{array}$ & $\begin{array}{c}d_{\text {50transient }} \\
(\mu \mathrm{m})\end{array}$ & $\begin{array}{c}\Delta_{\text {transient }} \\
(\%)\end{array}$ \\
\hline 1 & 3.7 & 2.3 & 38.7 & 2.3 & 38.7 \\
\hline 2 & 3.1 & 1.9 & 39.3 & 1.9 & 39.3 \\
\hline 3 & 2.9 & 1.8 & 39.7 & 1.7 & 41.4 \\
\hline 4 & 2.8 & 1.7 & 39.3 & 1.7 & 39.3 \\
\hline
\end{tabular}

TABLE VI. EXPERIMENTAL AND SIMULATED (PSEUDOTRANSIENT AND TRANSIENT REGIMES) REDUCED TOTAL EFFICIENCY (E'

\begin{tabular}{|c|c|c|c|c|c|}
\hline Case & $\begin{array}{c}\mathbf{E}_{\text {T experim. }}^{\prime} \\
(\%)\end{array}$ & $\begin{array}{c}\mathbf{E}^{\prime} \text { Tpse trans } \\
(\%)\end{array}$ & $\begin{array}{c}\Delta_{\text {pse trans }} \\
(\%)\end{array}$ & $\begin{array}{c}\mathbf{E}^{\prime}{ }_{\mathrm{T} \text { transient }} \\
(\%)\end{array}$ & $\begin{array}{c}\Delta_{\text {transient }} \\
(\%)\end{array}$ \\
\hline 1 & 36.9 & 58.2 & 57.8 & 57.3 & 55.3 \\
\hline 2 & 46.8 & 66.4 & 41.9 & 66.5 & 42.0 \\
\hline 3 & 51.7 & 68.2 & 31.1 & 69.3 & 44.0 \\
\hline 4 & 54.1 & 71.8 & 32.8 & 71.8 & 32.8 \\
\hline
\end{tabular}

An analysis of Tables V and VI shows that the pseudo transient and transient simulation data are very similar and compare reasonably well with the experimental results. Therefore, the pseudo transient regime is more appropriate, because the two-phase simulations took around 24 hours each to converge, whereas transient took around 42 hours. 


\section{v. Conclusions}

The stationary simulations showed to be inadequate to simulate hydrocyclones, because they do not provide the expected flow behaviour inside the device.

Simulations using pseudo transient and transient regimes give similar results. As transient regimes demand a much higher computational effort, it is recommended to use pseudo transient regime, when simulating hydrocyclones.

The simulations represented qualitatively well the experimental values. From a quantitative point of view, it can be said that simulated and experimental results for pressure drop and split ratio are close, whereas not so close for reduced cut sizes and reduced total efficiencies.

\section{References}

[1] S. Schuetz, G. Maier, M. Bierdel, M. Piesche, Investigation on the flow and separation behavior of hydrocyclones using computational fluid dynamics, Int. J. Miner. Process, vol. 73, 2004, pp 229-237.

[2] M. Narasimha, M. Brennan, P.N. Holtham, Large eddy simulation of hydrocyclone - prediction of air-core and shape, Int. J. Miner. Process, vol. 80, 2006, pp 1-14.

[3] A. Davailles, E. Climent, F. Bourgeois, Fundamental understanding of swirling flow patterns in hydrocyclone, Sep. Purif. Technology, vol. 92, 2012, pp 152-160.

[4] J. A. Delgadillo, R. K. Rajamani, A comparative study of three turbulence-closure models for the hydrocyclone problem, Int. J. Miner. Process., vol. 77, 2005, pp 217-230.

[5] S. Noroozi, S. H. Hashemabadi, CFD analysis of inlet chamber body profile effects on de-oiling hydrocyclone efficiency, Chem. Eng. Res. Des., vol. 89, 2011, pp 968-977.

[6] Y. R. Murthy, K. U. Bashkar, Parametric CFD studies on hydrocyclone, Powder Technol., vol. 230, 2012, pp 36-47.

[7] M. D. Slack, R. O. Prasad, A. Bakker, F. Boysan, Advances in cyclone modeling using unstructured grids, Chem. Eng. Res. Des., vol. 78, 2000, pp 1098-1104.

[8] Ansys Fluent 12.0, Theory Guide, Ansys, Inc, 2009.

[9] S. V. Patankar, Numerical Heat Transfer and Fluid Flow, Taylor \& Francis, 1980.

[10] H. K. Versteeg, W. Malalasekera, An Introduction to Computational Fluid Dynamics, 2nd Ed., Pearson Education Ltd., Harlow, 2007.

[11] M. A. P. Silva, R. A. Medronho, Bradley hydrocyclones: design and performance analysis, In: L. Svarovsky, M. Thew (eds.), Hydrocyclones: Analysis and Applications. Springer Sience + Bussiness, Dordrecht, 1992, pp. 3-13.

[12] Castilho, L. R. ; Medronho, R. A. . A simple procedure for design and performance prediction of Bradley and Rietema hydrocyclones. Minerals Engineering, vol. 13, pp. 183-191, 2000.

About Authors:

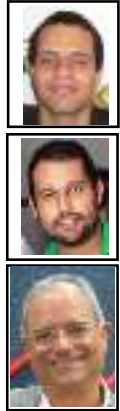

Eng. Rodrigo A. Petrone has a bachelor degree and MSc in chemical engineering both from UFRJ. At the moment, he is doing his D.Sc. course at UFRJ.

Eng. Rafael S. Oliveira has a bachelor degree and MSc in chemical engineering from Federal University of Rio de Janeiro - UFRJ.

Prof. Dr. Ricardo A. Medronho is a full professor at the Chem. Eng. Dept. of the Federal Univ. of Rio de Janeiro. $\mathrm{He}$ is a specialist in CFD applied to the oil industry and has supervised more than $50 \mathrm{MSc}$ and DSc students. 